\title{
Influence of SLA rapid prototyping process parameters on the forming
}

\author{
precision \\ Shi Yaru ${ }^{1, a}$, Cao Yan ${ }^{2, b^{*}}$ Wang Yongming ${ }^{3, c}$, Huang Liang ${ }^{4, d}$ \\ ${ }^{1,2,3,4}$ Department of Mechanical and Electronic Engineering, Xi'an Technological University, \\ Xi'an, China \\ ashi901006@163.com, bjantonyz@163.com, ’xiangxiang2050@163.com, \\ dimba11@163.com
}

\begin{abstract}
With the development of modern industry, Modern die technology is developing in the direction of high precision, high life, high productivity and complex structure. Therefore, the development of new die design and manufacturing technology is imperative. Light curing rapid prototyping technology is the earliest developed in rapid prototyping manufacturing technology. The technology has great prospects for the manufacture of irregular complex parts. In this paper, the theoretical analysis of the early data processing, the influence of various factors on the forming precision is analyzed. In order to make the parts get a higher precision, the 4 most important factors affecting the molding process parameters are obtained by the orthogonal experiment method: Spot diameter compensation, layer thickness, scanning speed, scanning distance of these four factors are analyzed. Get the most effective parameter setting, in order to achieve the purpose of improving the forming precision of the workpiece.
\end{abstract}

Key words: Rapid die manufacturing technology; SLA; Orthogonal test method; Optimal parameters.

\section{Foreword}

Liquid photosensitive resin selective curing, also known as stereo lithography process, is the earliest appearance, the most widely used a rapid prototyping technology. It uses liquid photosensitive resin as raw material, and the rapid prototyping technology based on light curing process is based on the principle of layered manufacturing. There are many factors that affect the forming precision of SLA rapid prototyping process. Scanning speed, scanning distance and laser power of SLA are determined by the scanning speed of forming process. When the layer thickness is slightly larger than the thickness of the solidified layer, there is no free shrinkage of the resin. With the thin layer of liquid resin curing flow phenomenon in the main tank, this drift phenomenon causes the forming part to be reduced, but it may cause the dislocation between the layer and the layer. When the layer thickness is slightly smaller than the thickness of the solidified layer, the layer and layer are adhered to, and the apparent degree of deformation will become larger with the increase of the thickness of the condensation layer ${ }^{[2]}$.

\section{SLA rapid prototyping process parameters and their effects}

The main process of SLA rapid prototyping process includes: Preliminary data processing, forming process and after processing three aspects. In the prophase of data processing, it is mainly the process of STL rapid prototyping process parameter setting, and the step effect problem. The most important part of the process is the setting of the process parameters. In the third chapter, the method of orthogonal test is used to determine. 


\subsection{Spot diameter}

UV light spot diameter is much larger than that of laser spot, which is used as a light curing rapid prototyping machine with UV light as light source. The general laser spot diameter is only $0.1 \mathrm{~mm}$, but the spot diameter of the ultraviolet light is $0.5 \mathrm{~mm}$, so it can not be regarded as a spot of light, The actual curing line width is equal to the size of the actual spot diameter under a certain scanning speed. The processing precision can be improved by using spot compensation in the scanning control program. In order to reduce or eliminate the positive deviation, the spot compensation is used to make the spot scanning path to the interior of the entity to a spot radius.

\subsection{STL rapid prototyping process parameter setting}

The model data of the face gear master model is processed into the STL data format that can be recognized by the rapid prototyping machine, The STL format is essentially with numerous small triangles to approximate curved surfaces and three-dimensional model of the original reduction. It is because of this approximate expression, the error - chord error control between STL format model and the original model. In view of this situation, the main solution is to reduce the chord error to increase the number of triangles, The STL model can be better fit, So as to achieve the purpose of improving the accuracy of STL model. Therefore, by referring to the relevant literature data, the optimal parameter setting method for converting the 3D model to STL format in UG environment is obtained(As shown in Table 1).

Table 1 conversion of 3D model into STL format common parameter setting method

\begin{tabular}{|c|c|}
\hline Software & Parameter setting \\
\hline UG & $\begin{array}{l}\text { 1)Document } \rightarrow \text { Leading-out } \rightarrow \text { STL } \rightarrow \text { Settype "Binary" } \\
\text { 2) Set triangle tolerance } 0.0025 \\
\text { 3)Set adjacent tolerance } 0.12 \\
\text { 4)Open automatic generation } \\
\text { 5)Close the normal display } \\
\text { 6)Open triangle display }\end{array}$ \\
\hline
\end{tabular}

\subsection{Molding direction and step effect of model}

Molding direction is in fact the part in the forming process of space in the form. Due to rapid prototyping using the principle of layered overlay manufacturing, The slice of a CAD model is composed of the upper and lower water plane and the middle surface, The contours of the upper and lower levels are not the same, In the forming process, it is composed of the upper layer of information on the level of the column to complete a thickness of T level production, In the process of machining, the phenomenon of "step effect" is bound to be generated when the cylinder is used to replace the arbitrary curved surface ${ }^{[1]}$.

At the same time, the maximum distance between the surface of the CAD model and the physical boundary along the solid surface is the layer thickness. From the above analysis, we can reduce the thickness of layers from the surface precision of parts, to improve the optimization of production direction.

\section{Experiment and data analysis}

This paper is to study the parameter setting of rapid prototyping of face gear, So in the print face gear, the core model (including the central axis model) of the cylinder bottom surface, the bottom model and the top model of the square bottom, Respectively with the molding platform to maintain the full contact of the model 
level of the model as part of the molding direction, This will not only be the "step effect" on the quality of the key to the master of the mold to minimize the impact, But also to avoid the design support for the mother mold piece surface to bring the further influence.

\subsection{Determination of process parameters}

Through theoretical analysis, it can be concluded that the factors such as scanning speed, scanning space, layer thickness and spot compensation are mainly caused by the low forming quality. In the following experiments, the four important process parameters are selected as the influencing factors, and the optimal setting parameters are obtained. In the whole experiment, we choose CPS(compact prototyping system) UV curing rapid prototyping machine - CPS250A, Its light curing material is used as XJTU - 9702.

\subsection{Specimen molding}

If the parameters of the test specimens are directly selected from the face gear, It brings difficulty to measure the dimension error of the back, Therefore, in order to facilitate the measurement of size and precision error, At the same time, it is convenient for data processing in the later period, The experimental design of a standard rectangular cube as the experimental object, there are $\mathrm{X}, \mathrm{Y}, \mathrm{Z}$ three directions, as shown in Figure 1.

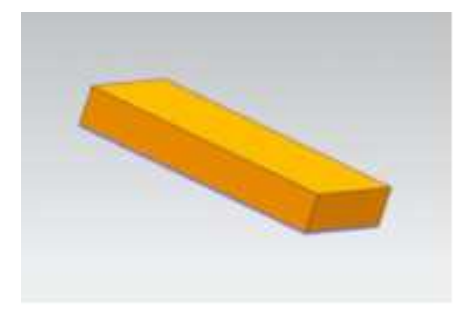

Figure 1 molding test specimens

\subsection{Orthogonal experimental design}

At present, the most widely used is the orthogonal test design method, It is a scientific method to study and deal with the multi factor experiment, The design problem has many advantages, such as long design period and so on:1)Pick out the most representative points in all the process parameters, with these characteristics of the "uniform dispersion" and "neat" characteristics of the test, Can reduce the number of experiments, but also can find the main factors from the complex factors.(2)Test of a few main technological parameters, Get the relevant data,then the statistical analysis method is used to analyze them, then the best conditions of the test and the production process can be obtained.

Four main process parameters are selected as factors, because the impact of each process parameter on the final test results is nonlinear, so the decision to use a different three factor levels of these four factors, as shown in Table 2. 
Table 2 factor level

\begin{tabular}{|c|c|c|c|c|}
\hline Test number & $\begin{array}{c}\text { Spot diameterA } \\
/ \mathrm{mm}\end{array}$ & $\begin{array}{c}\text { Lift height B } \\
/ \mathrm{mm}\end{array}$ & $\begin{array}{c}\text { Sweep speed C } \\
/ \mathrm{mm}^{-1}\end{array}$ & $\begin{array}{c}\text { ScanningintervalD } \\
/ \mathrm{mm}\end{array}$ \\
\hline 1 & 0.2 & 0.10 & 150 & 0.10 \\
3 & 0.5 & 0.15 & 300 & 0.15 \\
& 0.8 & 0.20 & 450 & 0.20 \\
\hline
\end{tabular}

According to the design principle of orthogonal table, It can be concluded that the best orthogonal table is $\mathrm{L}_{9}\left(3^{4}\right)$, which can be seen from the table, we need to design 9 experimental programs, do 9 experiments.

\subsection{Experimental results analysis}

According to the orthogonal experiment design, Process the 9 specimens, If some of the test piece is due to the impact of external factors and the formation of bad, Can be processed once again, If it is because of the parameters of the reasons for the formation of a poor quality or can not complete molding, you do not have to repeat the process.measurement and calculation of experimental results.

Measurement of the size of the X, Y, Z three directions of a molded part by using the three coordinate measuring machine, and the dimension error is obtained simultaneously, According to the above scheme for molding processing, to be fully cured after the size measurement, measurement of each feature size three times the final average, Calculation error and record, As shown in table 3. The formula for calculating the data in the table is as follows:

$$
\text { absolute error: } \varepsilon=\left|N^{\prime}-N\right| \quad \text { relative error: } \delta=\frac{\varepsilon}{N} \times 100 \%
$$

Type: $N$ - truth-value $; N$-Measured value

Table 3 orthogonal experimental data table

\begin{tabular}{|c|c|c|c|c|c|c|c|}
\hline \multirow{2}{*}{$\begin{array}{c}\text { Order } \\
\text { number }\end{array}$} & \multicolumn{3}{|c|}{ Influencing factor } & \multicolumn{3}{c|}{ Relative error } \\
\cline { 2 - 8 } & $\mathrm{A}$ & $\mathrm{B}$ & $\mathrm{C}$ & $\mathrm{D}$ & $\Delta \mathrm{X} \%$ & $\Delta \mathrm{Y} \%$ & $\Delta \mathrm{Z} \%$ \\
\hline 1 & 0.2 & 0.10 & 150 & 0.10 & 3.21 & 8.13 & 7.26 \\
2 & 0.2 & 0.15 & 300 & 0.15 & 1.11 & 4.16 & 6.39 \\
3 & 0.2 & 0.20 & 450 & 0.20 & 1.47 & 2.91 & 5.80 \\
4 & 0.5 & 0.10 & 150 & 0.20 & 1.40 & 2.00 & 6.68 \\
5 & 0.5 & 0.15 & 300 & 0.15 & 2.51 & 6.54 & 4.30 \\
6 & 0.5 & 0.20 & 450 & 0.10 & 0.67 & 2.91 & 5.21 \\
7 & 0.8 & 0.10 & 150 & 0.15 & 1.30 & 2.91 & 6.39 \\
8 & 0.8 & 0.15 & 300 & 0.20 & 0.27 & 0.14 & 6.39 \\
9 & 0.8 & 0.20 & 450 & 0.10 & 1.98 & 2.91 & 6.97 \\
\hline
\end{tabular}

The mean and range values of each dimension error are calculated according to the above table and the corresponding data are recorded as shown in table 4 . 
Table 4 error mean

\begin{tabular}{|c|c|c|c|c|c|}
\hline \multirow{2}{*}{\multicolumn{2}{|c|}{ Test error }} & \multicolumn{4}{|c|}{ Influencing factor } \\
\hline & & \multirow{2}{*}{$\begin{array}{l}\mathrm{A} \\
1.93\end{array}$} & \multirow{2}{*}{$\begin{array}{l}\mathrm{B} \\
1.97\end{array}$} & \multirow{2}{*}{$\begin{array}{l}\mathrm{C} \\
1.97\end{array}$} & \multirow{2}{*}{$\begin{array}{l}\mathrm{D} \\
1.95\end{array}$} \\
\hline \multirow{4}{*}{$\Delta \mathrm{X} \%$} & mean value 1 & & & & \\
\hline & mean value 2 & 1.52 & 1.29 & 1.29 & 1.64 \\
\hline & mean value 3 & 1.18 & 1.37 & 1.37 & 1.04 \\
\hline & range & 0.75 & 0.68 & 0.68 & 0.91 \\
\hline \multirow{4}{*}{$\Delta \mathrm{Y} \%$} & mean value 1 & 5.06 & 10.3 & 10.3 & 4.65 \\
\hline & mean value 2 & 3.81 & 3.61 & 3.61 & 4.53 \\
\hline & mean value 3 & 1.98 & 2.91 & 2.91 & 1.68 \\
\hline & range & 3.08 & 7.39 & 7.39 & 2.97 \\
\hline \multirow{4}{*}{$\Delta Z \%$} & mean value 1 & 6.48 & 6.77 & 6.77 & 6.48 \\
\hline & mean value 2 & 5.39 & 5.69 & 5.69 & 5.69 \\
\hline & mean value 3 & 6.58 & 5.99 & 5.99 & 6.29 \\
\hline & range & 1.19 & 1.08 & 1.08 & 0.79 \\
\hline
\end{tabular}

According to the data recorded in the table, respectively, draw range chart as shown in Figure 2 below.
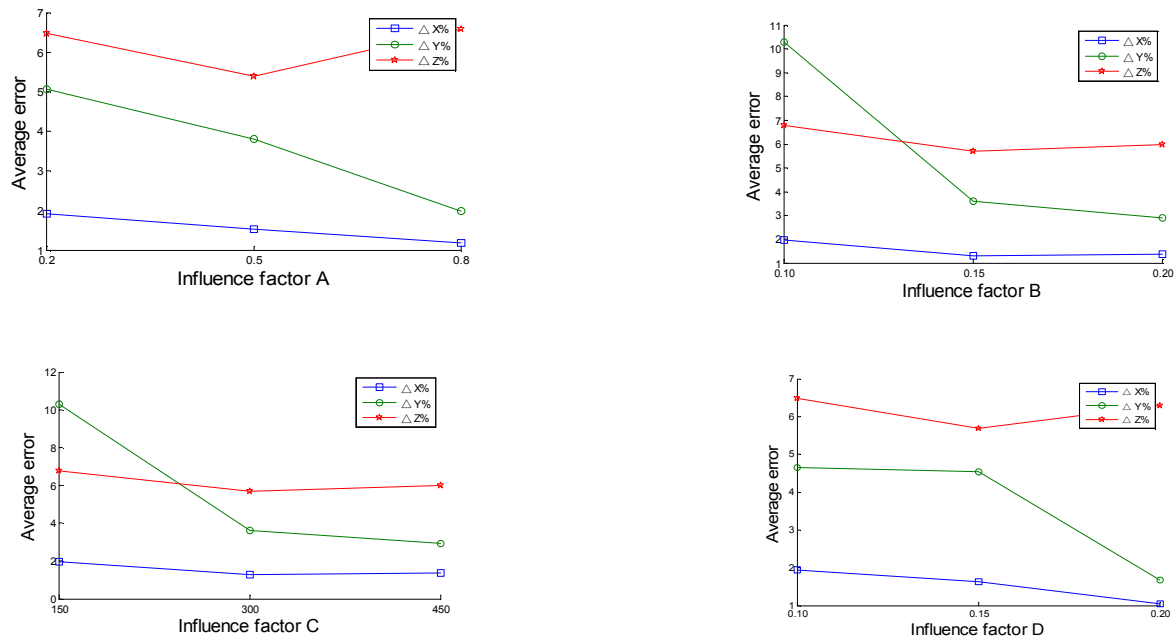

Figure $2 \Delta \mathrm{X} \%, \Delta \mathrm{Y} \%, \Delta \mathrm{Z} \%$ range chart

It can be seen that the different parameters of the combination will have a corresponding impact on the size of different directions, you can see that you want to get a higher precision, At the same time taking into account the appearance quality of the molded part, the optimum scheme was finally determined as $\mathrm{A}_{3} \mathrm{~B}_{2} \mathrm{C}_{2} \mathrm{D}_{3}$, Combination of process parameters: Scanning degree, $300 \mathrm{~mm} / \mathrm{s}$; Jump speed,350mm/s; Scanning spacing, $0.2 \mathrm{~mm}$; Support scanning speed,300mm/s; Waiting time between layers,5s; Spot compensation diameter, $0.2 \mathrm{~mm}$; Table feed rate, $4 \mathrm{~mm} / \mathrm{s}$; Layer thickness, $0.15 \mathrm{~mm}$; Table immersion depth, $6 \mathrm{~mm}$. The results of optimization of the process parameters of light curing rapid prototyping process, in the actual molding and production process, can significantly improve the quality of the molded parts, improve its accuracy. At the same time, to some extent, it improves the scientific process parameter setting of light curing rapid prototyping technology. The optimized results can also be applied to other UV rapid prototyping systems. 


\section{Conclusion}

This paper is based on SLA rapid prototyping technology, the pretreatment of three-dimensional model of face gear mold. The effect of different factors on the quality and efficiency of forming master molding rate to deal with three aspects of the process parameters of rapid prototyping face gear mold and face gear mold parts. Based on SLA, a rapid manufacturing process of gear master die for spur gears is presented, and the process is verified by experiments. The results show that the process can not only make the mold face gear with high quality in a relatively short period of time, the mother also made mold also has high strength, high temperature resistance and low cost, which has guiding significance for the rapid manufacturing technology in casting wax mold.

\section{Acknowledgements}

This project is supported by the special processing Key Laboratory of Shaanxi province(15JS041). The project name is "the key technology research of multi axis NC machining of spur gear. In the course of the study at the same time by the Beijing Sunplus technology company has given strong support. Here I want to express my sincere thanks.

\section{References}

[1] Dong Fang Li. Development and application of light curing rapid prototyping technology [J]. Journal of Beijing University of Technology.2015,12 (12): 1769-1774.

[2] Guangchun Wang, Ping Lu. Research and development of rapid prototyping precision of light curing [J]. Machine tools and hydraulic, 2006,05: 206-210.

[3] Kui Wang. Application and development of stereo light curing rapid prototyping technology [J]. New technology and new technology.2008,02 (02): 55-58.

[4] Tingfeng Yin. Analysis of dimensional error of light cured rapid prototyping [J]. Prospect of science and technology.2015: 157.

[5] Qinkun Xia. Rapid prototyping technology [J]. Journal of Changsha University, 2005,19 (5): 94-98.

[6] Xuejin Zhao. Research on model reconstruction method and molding process for increasing material manufacturing [D]. Shandong: Shandong University, 2013.

[7]Schlafer Sebastian, Riep Birgit, Griffen Ann et al..Filifactor alocis - involvement in periodontal biofilms[J]. BMC Microbiology, 2010, 10(1) 